\title{
ARTICLE
}

Received 9 Jan 2015 | Accepted 1 Apr 2015 | Published 11 May $2015 \quad$ DOl: 10.1038/ncomms8084

\section{Elucidation of $\mathrm{IgH} \mathrm{3}^{\prime}$ region regulatory role during class switch recombination via germline deletion}

\author{
Alexis Saintamand ${ }^{1,2}$, Pauline Rouaud ${ }^{1,2}$, Faten Saad ${ }^{1,2}$, Géraldine Rios ${ }^{3}$, Michel Cogné ${ }^{1,2,4}$ \& Yves Denizot Pr, $^{1,2}$
}

In mature B cells, class switch recombination (CSR) replaces the expressed constant $C \mu$ gene with a downstream $C_{H}$ gene. How the four transcriptional enhancers of the $\lg H 3^{\prime}$ regulatory region $\left(3^{\prime} R R\right)$ control CSR remains an open question. We have investigated $\lg G_{1}$ CSR in $3^{\prime} R R$-deficient mice. Here we show that the $3^{\prime} R R$ enhancers target the $S_{\gamma 1}$ acceptor region (and poorly the $S_{\mu}$ donor region) by acting on epigenetic marks, germline transcription, paused RNA Pol II recruitment, R loop formation, AID targeting and double-strand break generation. In contrast, location and diversity of $S_{\mu}-S_{\gamma 1}$ junctions are not affected by deletion of the $3^{\prime} R R$ enhancers. Thus, the $3^{\prime} R R$ controls the first steps of CSR by priming the $S$ acceptor region but is not implicated in the choice of the end-joining pathway.

\footnotetext{
${ }^{1}$ Université de Limoges, CRIBL, UMR 7276, Limoges 87000, France. ${ }^{2}$ CNRS UMR 7276, Limoges 87000, France. ${ }^{3}$ CNRS et Université de Nice Sophia Antipolis, Institut de Pharmacologie Moléculaire et Cellulaire, UMR 6097, Sophia Antipolis 06560, France. ${ }^{4}$ Institut Universitaire de France, Paris 87025 , France. Correspondence and requests for materials should be addressed to Y.D. (email: yves.denizot@unilim.fr).
} 
ymphopoiesis is coupled with programmed accessibility of Ig genes to transcription and to several major transcription-dependent DNA remodelling events ${ }^{1,2}$. Multiple cisregulatory elements located $5^{\prime}$ and $3^{\prime}$ of constant $(C)$ genes control B-cell ontogeny (schematised in the Supplementary Fig. 1a). Among $5^{\prime}$ elements, the intronic $E \mu$ enhancer is reported as a master control element of $V(D) J$ recombination $^{3,4}$. The $I g H 3^{\prime}$ regulatory region $\left(3^{\prime} R R\right)$, that encompasses the four transcriptional enhancers $h s 3 a, h s 1,2, h s 3 b$ and $h s 4$, controls $\mu$ transcription in mature $\mathrm{B}-\mathrm{cells}^{5}$, and is the master element controlling conventional class switch recombination $(\mathrm{CSR})^{6,7}$ and somatic hypermutation $(\mathrm{SHM})^{8}$ but without role on $V(D) J$ recombination ${ }^{9,10}$. CSR is a cis-deletion or trans-recombination process that allows the $C_{\mu}$ gene to be replaced in mice with one of the downstream $C_{\gamma 3}, C_{\gamma 1}, C_{\gamma 2 b}, C_{\gamma 2 a}, C_{\varepsilon}$ or $C_{\alpha}$ gene. These $C$ genes are preceded by repetitive target sequences for CSR termed switch $(S)$ regions. CSR thus usually joins the most $5^{\prime} S$ donor region $\left(S_{\mu}\right)$ and one of the downstream $S$ acceptor regions $\left(S_{\gamma 3}, S_{\gamma 1}, S_{\gamma 2 b}, S_{\gamma 2 a}\right.$, $S_{\varepsilon}$ or $S_{\alpha}$ ) (schematised in the Supplementary Fig. 1a). CSR is a complex process involving epigenetic histone modifications for transcriptional accessibility, germline transcription, pausing of RNA Pol II, R loop formation, AID recruitment, AID-induced DNA double-strand breaks (DSBs) and their repair by means of end joining ${ }^{1-15}$. CSR uses the classical non-homologous end joining (C-NHEJ) pathway that predominantly joins ends that lack homology (direct joints). However in C-NHEJ-deficient conditions, an alternative end-joining (A-EJ) pathway is left, which predominantly joins ends by using short homologies found in the proximity of broken ends (microhomology-based repair) ${ }^{11,13}$. The $3^{\prime} R R$ is crucial for conventional $\operatorname{CSR}^{6,7}$ but its mechanistic contribution remains enigmatic. The main conclusions drawn from knock-out mice are that the $3^{\prime} R R$ plays a major role in promoting synapsis between $S$ regions targeted by $\mathrm{CSR}^{16}$, and plays a partial role in promoting germline transcription of $S$ regions initiating at $I$ promoters ${ }^{6,17,18}$. Whether the chromatin structure of $S$ regions or the process of their repair after CSR are also dependent from the $3^{\prime} R R$ is currently unknown. The $\operatorname{IgG}_{1}$ class displays a special status with regard to $3^{\prime} R R$ mutations, since it was the only Ig class whose expression was preserved after the first reported partial $3^{\prime} R R$ alterations or truncations ${ }^{17,18}$. Even after complete deletion of the $3^{\prime} R R$, while CSR to all other class-switched Ig was nearly abolished, residual low-level CSR to $\mathrm{IgG}_{1}$ was maintained ${ }^{6}$. We thus now take advantage of this preserved $\operatorname{IgG}_{1}$ switching in $3^{\prime} R R$-deficient mice to explore whether it reveals additional $3^{\prime} R R$-dependent mechanistic features during CSR. We report here that, even if some $\operatorname{IgG}_{1}$ CSR still occurs, the $3^{\prime} R R$ defect impacts the $S_{\gamma 1}$ acceptor region (rather than the donor $S_{\mu}$ region) in multiple aspects that precede CSR. This includes alterations of epigenetic marks, germline transcription, $\mathrm{R}$ loop formation, paused RNA Pol II, AID targeting, and generation of DSBs. In contrast, once DSBs are generated, their repair is completely normal in $3^{\prime} R R$-deficient animals. Altogether, this study precisely maps the activity of the $3^{\prime} R R$ at the early phases of CSR, until the generation of DSBs, and shows that it has no contribution in the process of DNA repair between synapsed broken ends.

\section{Results}

Deletion of the $\mathbf{3}^{\prime} \boldsymbol{R} \boldsymbol{R}$ impairs $\boldsymbol{C}_{\boldsymbol{\mu}}-\boldsymbol{C}_{\gamma \mathbf{1}} \mathrm{CSR}$. The $I g H C_{\gamma 1}$ gene has long been claimed to carry some specific regulatory elements and notably an upstream $I_{\gamma 1}$ enhancer ${ }^{19}$. While the $I g H 3^{\prime} R R$ is the major cis-element promoting synapsis between $S$ regions and recruiting AID to the $\mathrm{IgH}$ locus, several previous descriptions of $3^{\prime} R R$ disruptions in the mouse indicated some persistence of CSR to $C_{\gamma 1}^{6,16-18}$, and we thus decided to analyse in details the molecular features of this residual $3^{\prime} R R$-independent CSR. We confirmed that splenocytes from $3^{\prime} R R$-deficient mice showed a dramatically reduced ability to secrete $\operatorname{IgG}_{1}$ in vitro in response to LPS + IL4 (Fig. 1a), which likely results from both decreased CSR in B-cells and the known defect of Ig secretion in plasma cells from such mice ${ }^{6}$. Parallel flow cytometry experiments evaluating membrane $\mathrm{IgG}_{1}$ expression in B-cells confirmed that the deletion of the $3^{\prime} R R$ did not abolish but reduced by $>90 \%$ in vitro $\operatorname{IgG}_{1}$ CSR (Fig. 1b). This strong but incomplete defect was also indicated by Southern blot experiments (full blots are included in the Supplementary Fig. 2) evaluating hybrid $S_{\mu}-S_{\gamma 1}$ junctions in $3^{\prime} R R$-deficient mice (Fig. 1c). Junctions were first amplified using a touch-down PCR followed with a nested PCR and revealed after hybridization with a ${ }^{32} \mathrm{P}$-labelled probe. DNA from AID-deficient B-cells (devoid of any CSR) was used as germline control DNA. The $\operatorname{IgG}_{1}$ CSR defect was also evidenced by real-time-PCR evaluation of post-switch $\operatorname{IgG}_{1}$ transcripts (Fig. 1d). Finally, serum $\operatorname{IgG}_{1}$ levels paralleled results obtained after in vitro stimulation (Fig. 1e) and confirmed that, altogether, the deletion of the $3^{\prime} R R$ strongly but only partially blocks $\operatorname{IgG}_{1}$ CSR.

Intra $S_{\mu}$ deletion in $\mathbf{3}^{\prime} \boldsymbol{R} R$-deficient $\mathbf{B}$ cells. It could be argued that the few $S_{\mu}-S_{\gamma 1}$ joints found in $3^{\prime} R R$-deficient B-cells mask a defect in end-joining that would result in aborted CSR (and, therefore, no joint to analyse). To test this hypothesis we analysed intra $S_{\mu}$ deletions that frequently happen in mature B-cells during $\mathrm{CSR}^{20}$. By using a PCR amplifying the whole $S_{\mu}$ region followed by Southern blotting, we checked that B-cell stimulation yielded fragments of different lengths corresponding to partial deletion of $S_{\mu}$ during CSR. A similar pattern was found for both $w t$ mice and $3^{\prime} R R$-deficient mice (Fig. 2a), eliminating any global defect in end joining in $3^{\prime} R R$-deficient mice and also showing that $S_{\mu}$ is efficiently targeted by the CSR machinery in stimulated $3^{\prime} R R$-deficient B cells.

Analysis of $S$-junctions in residual $C_{\mu}-C_{\gamma 1}$ CSR. To analyse $S$-junctions, the amplified PCR $S_{\mu}-S_{\gamma 1}$ fragments were cloned, sequenced and aligned with the germline $S_{\mu}$ and $S_{\gamma 1}$ sequences (Fig. 2b and Supplementary Table 2). The deletion of the $3^{\prime} \mathrm{RR}$ had no effect on the structure of $S$ junctions with regards to the relative amounts of direct joints, the frequency and length of microhomologies and the frequency of DNA insertion at the junction and of complex junctions. This suggests that beyond the AID targeting, DSBs and $S_{\mu}-S_{\gamma 1}$ synapsis steps, the late CSR resolution step is completely $3^{\prime} R R$-independent and remains unbiased in the choice between either the C-NHEJ or the A-EJ pathways for repairing broken DNA ends. We then analysed whether the absence of the $3^{\prime} R R$ enhancers affected the position of the $S_{\mu}$ and $S_{\gamma 1}$ breakpoints, which might indicate changes in the targeting or the synapsis of these regions. $S_{\mu}$ breakpoints appeared unaltered, with the vast majority of them located in the $5^{\prime}$ part (0-600 bp) of $S_{\mu}$ (Fig. 3): 97\% (33/34) and 91\% (21/23) for $w t$ and $3^{\prime} R R$-deficient mice, respectively (Fig. 2c). The $3^{\prime} R R$ deletion by contrast affected the location of $S_{\gamma 1}$ breakpoints since 94\% (32/34) of breaks cloned from $w t$ cells were located in the $3^{\prime}$ part (0-480 bp) of $S_{\gamma 1}$, while only $65 \%(15 / 23)$ were included in this segment in $3^{\prime} R R$-deficient cells. The pattern of AID targeting that initiates the formation of DSBs is thus $3^{\prime} R R$-independent within $S_{\mu}$ but partially $3^{\prime} R R$-dependent within $S_{\gamma 1}$. The increased representation of DNA breaks in the $3^{\prime}$ part of $S_{\gamma 1}(>480 \mathrm{bp})$ was not linked to the presence of microhomologous sequences: $2 / 4$ and $6 / 11$ direct junctions for $w t$ and $3^{\prime} R R$-deficient mice, respectively. We conclude that the recombination of $S_{\mu}$ with $S_{\gamma 1}$ in $3^{\prime} R R$-deficient $B$ cells does not depend on the presence of microhomologous sequences and that the $3^{\prime} R R$ is not involve in 
the resolution of CSR nor in the choice between C-NHEJ and A-EJ pathways.

Influence of the $3^{\prime} R R$ on AID recruitment during $C_{\mu}-C_{\gamma 1}$ CSR. Before the occurrence of DSBs, CSR is initiated by AID and the initial outcome of AID targeting can be the occurrence of base substitutions following cytidine deamination ${ }^{12,14,15,21}$. To gain an insight into this initial targeting, we analysed mutations in $S$ regions and observed that both the $S_{\mu}$ donor and $S_{\gamma 1}$ acceptor regions are less targeted by AID during $\operatorname{IgG}_{1}$ CSR in $3^{\prime} R R$-deficient mice as compared with $w t$ animals (Fig. 2d). This showed up with mutation rates falling at 55 and $30 \%$ of their $w t$ levels for $S_{\mu}$ and $S_{\gamma 1}$, respectively. This observation suggests a lower recruitment of AID in $S$ regions in $3^{\prime} R R$-deficient animals, which is indeed also indicated by ChIP experiments showing a significantly decreased AID loading at both the $S_{\mu}$ and $S_{\gamma 1}$ regions (after 2 days LPS + IL4 in vitro stimulation) in $3^{\prime} R R$-deficient mice compared with $w t$ mice (Fig. 3a). A crucial step of CSR is the processing of AID lesions into DSBs, as a specific feature of $S$ regions ${ }^{14,15}$. Ligation-mediated PCR (LM-PCR, see Supplementary Fig. 1b) was used to highlight DSBs in $S_{\mu}$ and $S_{\gamma 1}$. Thus, extracted genomic DNA was treated with T4 DNA polymerase yielding blunt DNA ends, then ligated with T4 DNA ligase with a double-strand anchor linker ${ }^{22}$. DSBs were detected by semi-nested PCR (primers targeting the linker sequence and a primer specific to $S_{\mu}$ or $S_{\gamma 1}$ ) followed by hybridization with a ${ }^{32}$ P-labelled probe. LM-PCR highlighted a small reduction of DSBs in $S_{\mu}$ but a dramatic one in $S_{\gamma 1}$ in $3^{\prime} R R$-deficient mice compared with $w t$ mice (Fig. $3 \mathrm{~b}$; full blots are included in the Supplementary Fig. 2). Impaired induction of DNA lesions during CSR was suggested in patients to influence end joining ${ }^{23}$. It is obviously not the case in $3^{\prime} R R$-deficient mice.

The substrate for AID is single-strand DNA (ssDNA) which is generated by germline transcription of $S$ regions and Ig constant regions on both the transcribed and non-transcribed strands. Real-time PCR analysis only indicated a partial reduction of $I_{\mu}-C_{\mu}$ and $I_{\gamma 1}-C_{\gamma 1}$ transcripts in $3^{\prime} R R$-deficient mice (Fig. $3 \mathrm{c}$ ), as previously suggested by semi-quantitative $\mathrm{PCR}^{6}$. This shows that the $3^{\prime} R R$ does not promote CSR only by fostering germline transcription. Transcription through $S$ regions generates $\mathrm{R}$ loops in which the RNA stably hybridizes to the template strands, displacing the non-template strand as ssDNA ${ }^{14,15}$. For $\mathrm{R}$ loops experiments (see Supplementary Fig. 1c), extracted DNA was treated with bisulfite. Thus, only C located on ssDNA patchs (that is, in R loops) could be converted in U. Bisulfite-treated DNA was a

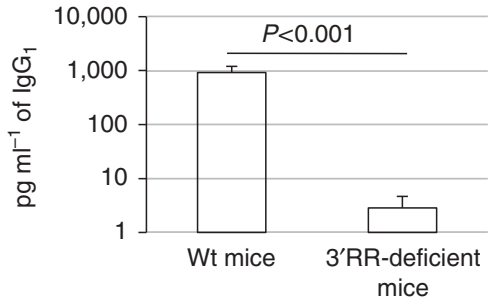

C

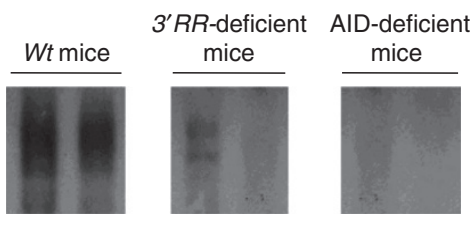

b
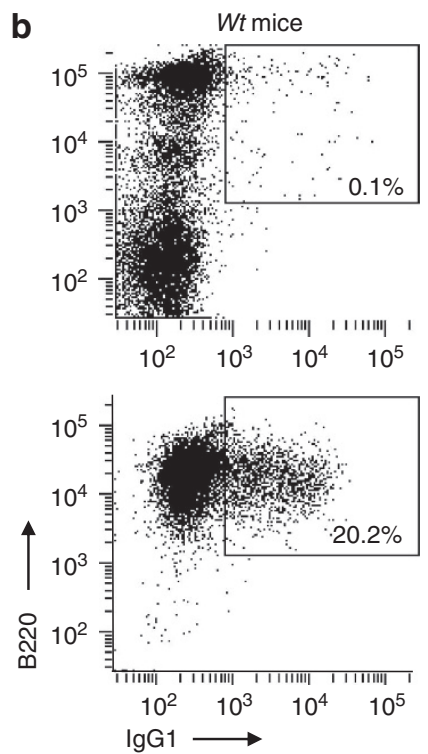

d

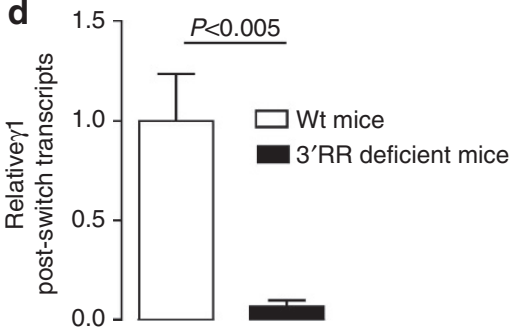

$3^{\prime} R R$-deficient mice
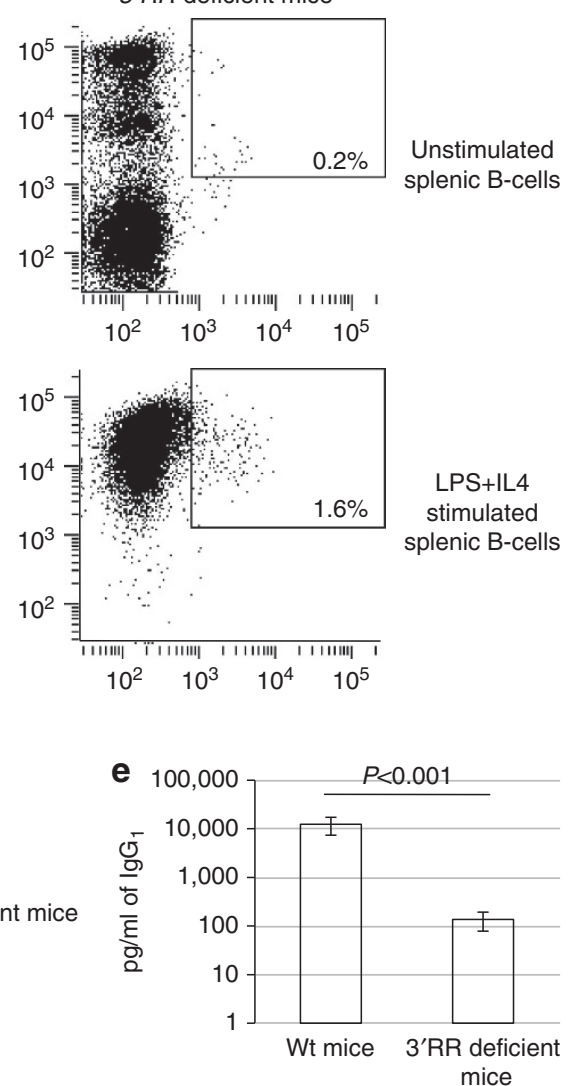

Figure 1 | Influence of the $\mathbf{3}^{\prime} \mathbf{R R}$ deletion on $\mathbf{I g G}_{\mathbf{1}} \mathbf{C S R}$ and secretion. (a) ELISA analysis of $\lg \mathbf{G}_{\mathbf{1}}$ in supernatants of 3 days LPS + IL4 cultured B-cells. Data are the mean \pm s.e.m. of 8 experiments with 1 mouse (Mann-Whitney $U$-test for significance). (b) B splenocytes of wt and $3^{\prime} R R$-deficient mice were isolated (upper panel) and stimulated with LPS + IL-4 for 3 days (lower panel). Cells were labelled with anti-B220-APC antibodies and anti-IgG 1 -FITC antibodies. Percentage of $\mathrm{B}_{2} 2 \mathrm{O}^{+} \mathrm{IgG}_{1}^{+}$cells is reported in the gate. One representative experiment out of four (one mouse per experiment) is shown. (c) Southern blot analysis of $S_{\mu}-C_{\gamma 1}$ junctions amplified by PCR and hybridized with a $5^{\prime} C_{\gamma 1}$ probe from 3 days LPS + IL4 stimulated splenocytes from wt, 3'RR-deficient mice and AID-deficient mice. DNA from AID-deficient B-cells (devoid of any CSR) was used as germline control DNA. Fifty nanograms and $20 \mathrm{ng}$ of DNA were used for PCR experiments, respectively. One representative experiment out of four (one mouse per experiment) is shown. (d) Real-time PCR analysis of post switched lgG 1 transcripts in 3 days LPS + IL4 cultured B cells. Values were normalized to Gapdh transcripts. Data are the mean \pm s.e.m. of 8 to 11 independent experiments with one mouse (Mann-Whitney U-test for significance). (e) ELISA analysis of IgG in 12-week-old mice sera. Data are the mean \pm s.e.m. of 8 mice for each genotype (Mann-Whitney $U$-test for significance). 
a

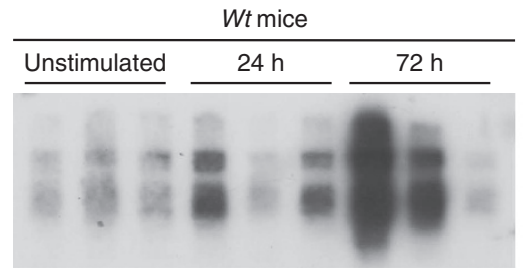

3'RR-deficient mice

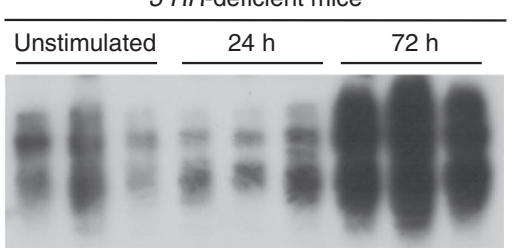

b

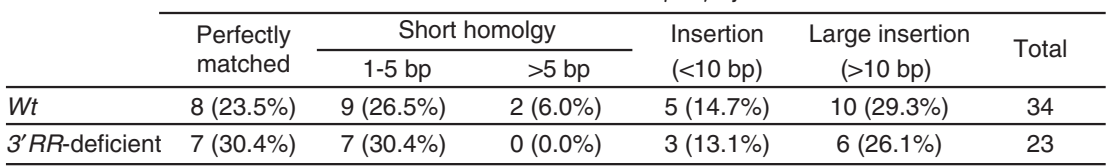

C

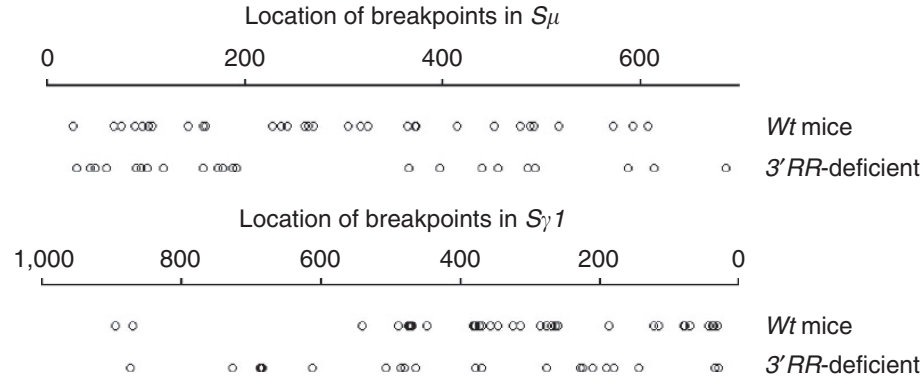

d

\begin{tabular}{llccc} 
& & \multicolumn{3}{c}{ Characterization of mutations } \\
\cline { 3 - 5 } & & $\begin{array}{c}\text { Mutated/total } \\
\text { sequences }\end{array}$ & $\begin{array}{c}\text { Total mutations/total } \\
\text { bps }\end{array}$ & $\begin{array}{c}\text { Total mutations/mutated } \\
\text { bps }\end{array}$ \\
\cline { 2 - 5 } & $S_{\mu}$ & $19 / 34(55.88 \%)$ & $68 / 9763(0.69 \%)$ & $68 / 5520(1.23 \%)$ \\
& $S_{\gamma} 1$ & $19 / 34(55.88 \%)$ & $77 / 10919(0.70 \%)$ & $77 / 6525(1.18 \%)$ \\
& Total & $24 / 34(70.58 \%)$ & $145 / 20682(0.70 \%)$ & $145 / 12045(1.20 \%)$ \\
\hline \multirow{2}{*}{$3{ }^{\prime} R R$-deficient } & $S_{\mu}$ & $9 / 23(39.13 \%)$ & $19 / 6048(0.31 \%)$ & $19 / 3457(0.55 \%)$ \\
& $S_{\gamma} 1$ & $7 / 23(30.43 \%)$ & $29 / 9701(0.30 \%)$ & $29 / 3506(0.83 \%)$ \\
& Total & $15 / 23(65.21 \%)$ & $48 / 15749(0.30 \%)$ & $48 / 6963(0.69 \%)$ \\
\hline
\end{tabular}

Figure 2 | Influence of the $\mathbf{3}^{\prime} \boldsymbol{R} \boldsymbol{R}$ deletion on diversity and mutations of $\boldsymbol{S}_{\boldsymbol{\mu}}$ - $\boldsymbol{S}_{\boldsymbol{\gamma} \mathbf{1}}$ junctions. (a) Intra $\boldsymbol{S}_{\boldsymbol{\mu}}$ deletion in $3^{\prime} R R$-deficient B cells. Splenocytes were LPS + IL4 stimulated for 24 or $72 \mathrm{~h}$. PCR amplification of the whole $S \mu$ region was followed by Southern blotting for detection of fragments of different length, more abundantly after B-cell stimulation, corresponding to partial deletion of $S_{\mu}$ during CSR. A similar pattern is found for wt and $3^{\prime} R R$-deficient mice. Results from three mice out of six for each genotype are reported. (b) B splenocytes were stimulated with LPS + IL-4 to generate $C_{\mu}-C_{\gamma 1}$ CSR. $S_{\mu}-S_{\gamma 1}$ junctions were cloned and sequenced. Percentage of junctions with insertion and junctional microhomology are indicated. Data are pooled from 6 independent experiments with 1 mouse per experiment for wt mice and 10 independent experiments with 1 mouse for $3^{\prime} R R$-deficient mice. All junctions are reported in the Supplementary Table 1. (c) Location of $S_{\mu}-S_{\gamma 1}$ breaks during in vitro lgG $G_{1}$ CSR (6wt mice and 10 3'RR-deficient mice; same junctions and mice as in (a). (d) Number of mutations and mutation frequency in the donor region $\left(S_{\mu}\right)$ and the acceptor region $\left(S_{\gamma 1}\right)$ during $C_{\mu}-C_{\gamma 1} C S R .34$ wt junctions (data are pooled from 6 independent experiments with 1 mouse per experiment) and $233^{\prime} R R$-deficient junctions (data are pooled from 10 independent experiments with 1 mouse per experiment; same junctions and mice as in $(\mathbf{b}, \mathbf{c})$ ).

then amplified by PCR and sequenced to detect R loops in $S_{\mu}$ and $S_{\gamma_{1}}$ regions. As shown in Fig. 3d, the formation of R loops was markedly altered in $S_{\gamma 1}$ region but not in $S_{\mu}$ region of $3^{\prime} R R$ deficient mice (each long line represents an independent sequence and the small vertical bars on each line indicate a $\mathrm{C}$ on the sequence converted to a $\mathrm{T}$, indicating that the sequence was in a single-strand conformation). R loops in the $S_{\mu}$ region appear to be even longer in $3^{\prime} R R$-deficient mice, a result that might be taken as an indication of the reduced CSR efficiency due to the reduced $S_{\gamma 1}$ CSR priming. AID was shown to be in a complex with RNA Pol II (Pol II P-ser2) and paused RNA Pol II (Pol II P-ser5) ${ }^{24}$. ChIP experiments showed a weak decrease in the load of RNA Pol II (but not paused RNA Pol II) in the $I_{\mu}-S_{\mu}-C_{\mu}$ region (Fig. 4a,b). By contrast, $3^{\prime} R R$-deficient cells showed dramatically decreased binding of RNA Pol II and paused RNA Pol II throughout the $P_{\gamma 1}-I_{\gamma 1}-S_{\gamma 1}-C_{\gamma 1}$ region (Fig. 4a,b). Collectively, our data indicated that the $3^{\prime} R R$ is of key importance for the regulation, in $S_{\gamma 1}$ region, of RNA Pol II recruitment, transcriptional activity and pausing, that is known prerequisites of AID recruitments. The lower accumulation of AID in the $S_{\gamma 1}$ region of $3^{\prime} R R$-deficient mice translates into lower amounts of DSBs and thus reduced efficiency of $\operatorname{IgG}_{1}$ CSR. Lower $S_{\gamma 1}$ RNA Pol II targeting and $I_{\gamma_{1}-} C_{\gamma 1}$ germline transcription are also in agreement with reduced length of $S_{\gamma 1} \mathrm{R}$ loops. Of interest, the $S_{\mu}$ donor region was markedly less affected by the $3^{\prime} R R$ deletion than the $S_{\gamma 1}$ acceptor region, suggesting that $S_{\mu}$ is the less $3^{\prime} R R$-dependent $S$ region of the IgH locus at both the level of transcription and AID targeting. Reduced $S_{\mu}-S_{\gamma 1}$ CSR in $3^{\prime} R R$-deficient mice thus mostly involves decreased accessibility and less frequent DSBs in the acceptor $S_{\gamma 1}$ than in the donor $S_{\mu}$ region.

Chromatin remodelling in the absence of the $\operatorname{IgH} 3^{\prime} R R$. Histone $\mathrm{H} 3$ and $\mathrm{H} 4$ modifications (acetylation and methylation) are 

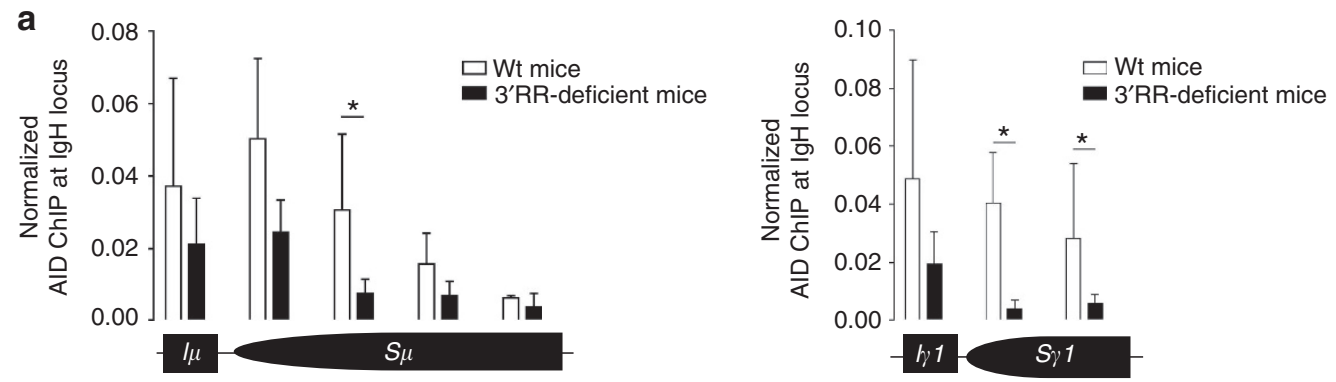

b
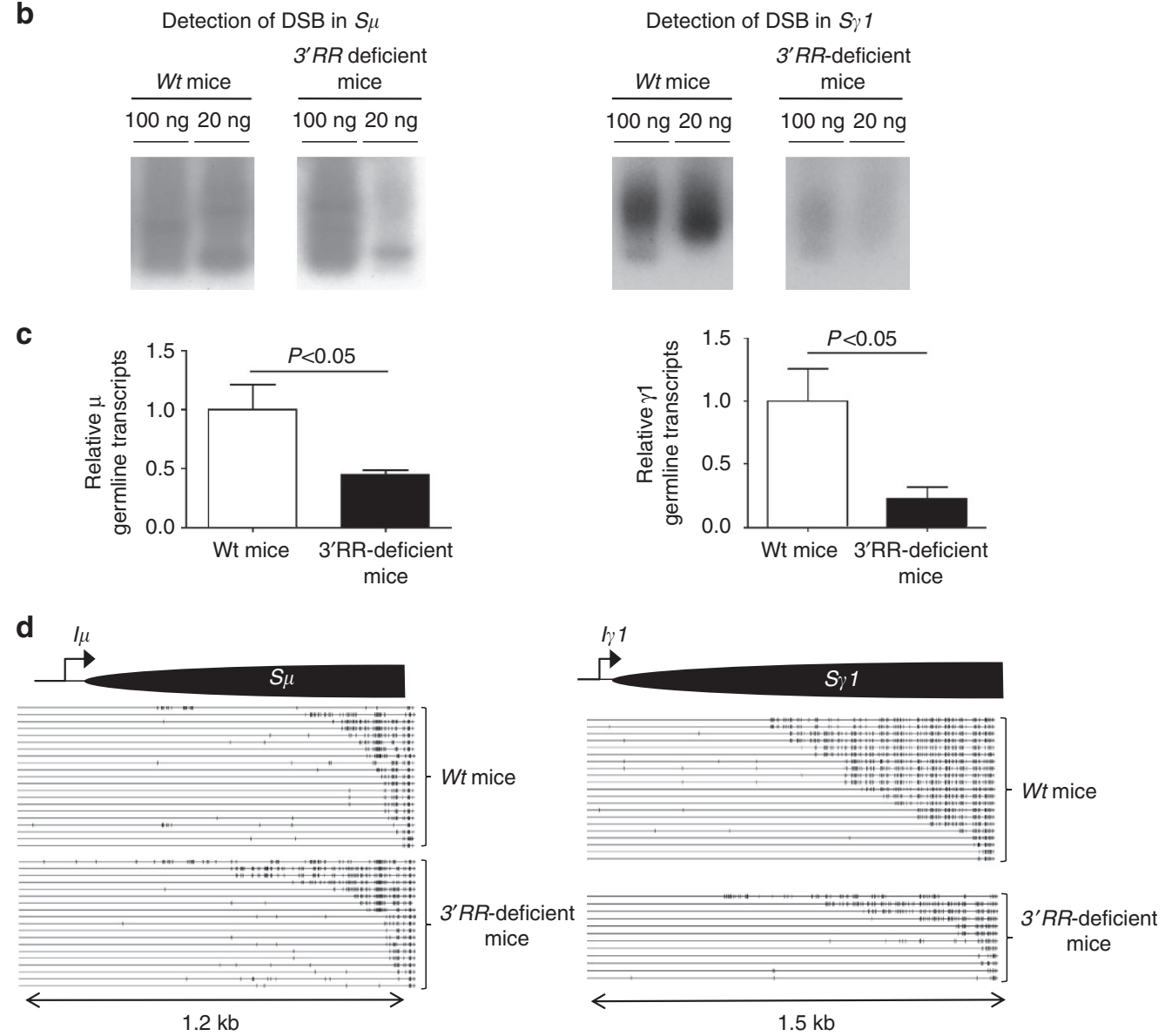

Figure 3 | AID and CSR in $\mathbf{3}^{\prime} \boldsymbol{R}$ R-deficient mice. (a) AID ChIP assays were performed with splenic B cells from $3^{\prime} R R$-deficient and wt mice. Cells were stimulated with LPS + IL-4 for 2 days. Background signals from mock samples with irrelevant antibody were subtracted. Values were normalized to the total input DNA. Data are the mean \pm s.e.m. of six independent experiments with two mice. ${ }^{\star} P<0.05$ (Mann-Whitney U-test). (b) Ligation-mediated PCR. Splenic B cells were stimulated with LPS + IL-4 for 2 days. Genomic DNA from wt and 3 'RR-deficient mice were treated with T4 DNA polymerase (T4 Pol), ligated with T4 DNA ligase and probed for double-stranded breaks in $S_{\mu}$ and $S_{\gamma 1}$ by semi-nested PCR. Reactions with 100 and 20 ng of DNA are shown. Data are representative of four experiments each with one mouse per genotype. (c) Real-time PCR analysis of $I_{\mu}-C_{\mu}$ and $I_{\gamma 1}-C_{\gamma 1}$ transcripts in 3 days LPS + IL4 cultured B cells. Values were normalized to Gapdh transcripts. Data are the mean \pm s.e.m. of 8 to 11 independent experiments with 1 mouse (Mann-Whitney U-test for significance). (d) Detection of R loops in $S_{\mu}$ and $S_{\gamma 1}$. Cells were stimulated with LPS + IL-4 for 2 days. DNA was extracted, bisulfited, treated and sequenced to detect single strand in $S_{\mu}$ and $S_{\gamma 1}$ regions. Each long line represents an independent sequence. The small vertical bars on each line indicate a $\mathrm{C}$ on the sequence converted to a $\mathrm{T}$, indicating that the sequence was in a single-strand conformation. Pooled results from six independent experiments each with one mouse per genotype.

implicated in the targeting of the CSR machinery (including AID and RNA Pol II) to $S$ regions primed for $\mathrm{CSR}^{25-28}$. Altogether with DNA transcription, this remodelling of chromatin in $S$ regions constitutes a hallmark of the accessibility to CSR factors. As shown in Fig. 5, except for acetylated lysine 9 in histone $\mathrm{H3}$ $(\mathrm{H} 3 \mathrm{~K} 9 \mathrm{ac})$, levels of $\mathrm{H} 3$ acetylation (H3ac), $\mathrm{H} 4$ acetylation $(\mathrm{H} 4 \mathrm{ac})$ and trimethylated lysine 4 in histone $\mathrm{H} 3$ (H3K4me3) were not affected by the deletion of $3^{\prime} R R$ enhancers in the $I_{\mu}-S_{\mu}-C_{\mu}$ region during IgG 1 CSR induced by LPS + IL4 stimulation. In contrast, $\mathrm{H} 3 \mathrm{ac}, \mathrm{H} 3 \mathrm{~K} 4 \mathrm{me} 3$ and $\mathrm{H} 3 \mathrm{~K} 9 \mathrm{ac}$ were dramatically lowered in the $P_{\gamma 1}-I_{\gamma 1}-S_{\gamma 1}-C_{\gamma 1}$ region (while $\mathrm{H} 4 \mathrm{ac}$ was unchanged) (Fig. 5). Interestingly, the $\mathrm{H} 3 \mathrm{~K} 4 \mathrm{me} 3$ and $\mathrm{H} 3 \mathrm{~K} 9 \mathrm{ac}$ marks are required for efficient CSR and further AID recruitment ${ }^{27,28}$. As reported above for AID and RNA Pol II, this study of the epigenetic marks required for CSR shows that the $3^{\prime} R R$ mostly acts on accessibility of the acceptor $S_{\gamma 1}$ rather than the donor $S_{\mu}$ region during $S_{\mu}-S_{\gamma 1}$ 

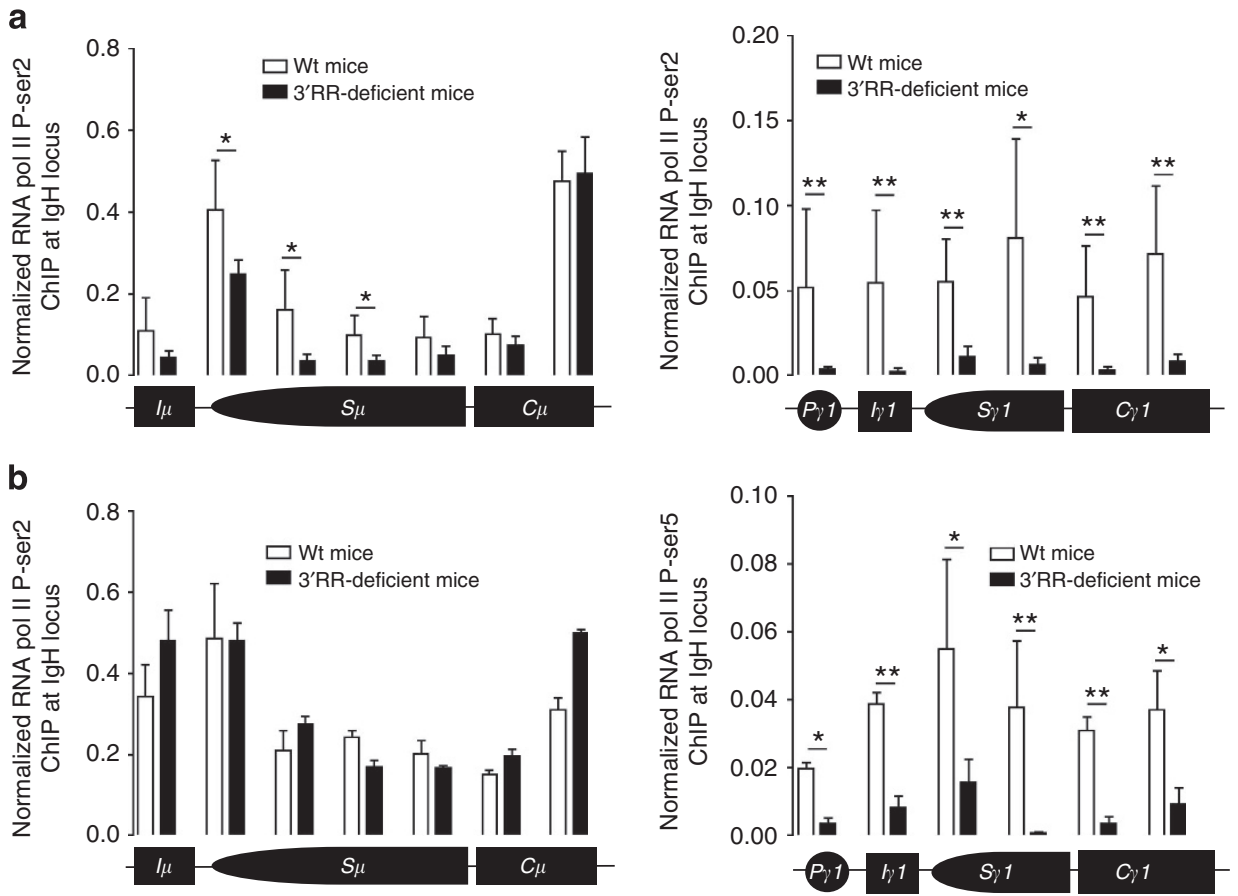

Figure 4 | RNA Pol II during CSR in $\mathbf{3}^{\prime} \boldsymbol{R} \boldsymbol{R}$-deficient mice. ChIP assays were performed with splenic B cells from $3^{\prime} R R$-deficient and wt mice. Cells were stimulated with LPS + IL-4 for 2 days. RNA Pol II P-ser 2 (a). RNA Pol II P-ser 5 (b). Background signals from mock samples with irrelevant antibody were subtracted. Values were normalized to the total input DNA. Data are the mean \pm s.e.m. of three experiments with two mice for each genotype. ${ }^{\star} P<0.05$ and ${ }^{\star \star} P<0.01$ (Mann-Whitney $U$-test).

CSR. This suggests that a reduction in histone acetylation is the most upstream defect after $3^{\prime} R R$ deletion. The levels of histone acetylation are reversibly controlled by the balanced counteraction of histone acetyltransferases (HATs) and histone deacetylases (HDACs). Although HDAC inhibitor treatment have been used to reverse the heterochromatin silencing of $I g$ minigenes ${ }^{29}$, these drugs are potent inhibitors of the $3^{\prime} R R$ in $\mathrm{B}$ cells. Thus, treatment of $\mathrm{B}$ cells with the HDAC inhibitor trichostatin A represses $\operatorname{IgH}$ gene transcription, CSR and Ig synthesis in B splenocytes ${ }^{30}$. We confirmed that IgG $_{1}$ CSR was strongly decreased in activated B-cells treated with trichostatin A, valproic acid or SAHA; three HDAC inhibitors (Supplementary Fig. 3). Therefore, ChIP assays of epigenetic marks should be preferred over HDAC inhibitor treatments to study CSR in the $\mathrm{IgH}$ locus. How $3^{\prime} \mathrm{RR}$ recruits histone acetyltransferases (if any) remains an open question. Studies suggested that levels of histone acetylation in the $\mathrm{IgH}$ locus are predominantly controlled by HDACs, but that the various HDACs might have opposite effects. ChIP experiments reported HDAC1 recruitment by the central $h s 1,2$ enhancer of the $3^{\prime} R R^{30}$ and $I g H$ transcription decreased in HDAC1-deficient chicken $\mathrm{B}$ cells ${ }^{31}$. By contrast, HDAC2 inhibited transcription and recombinational activities at the $\operatorname{IgH}$ locus ${ }^{31}$.

Effect of the $3^{\prime} R R$ on $S_{\gamma 3,2 b, \varepsilon}$ acceptor regions during CSR. Other CSR-related $S$ acceptor regions are located all along the $I g H$ locus (Supplementary Fig. 1a). As previously reported the $3^{\prime} R R$ not only interacts with $S_{\gamma 1}$ but also other $S$ regions including $S_{\gamma 3}$, $S_{\gamma 2 \mathrm{~b}}$ and $S_{\varepsilon}{ }^{16}$. We evaluated what happens for $S_{\gamma 3}, S_{\gamma 2 \mathrm{~b}}$ and $S_{\varepsilon}$ after appropriate in vitro CSR stimulations. Similarly to $S_{\gamma_{1}}$, we found a dramatic decrease of AID, pol II, paused pol II recruitments and $\mathrm{H} 3 \mathrm{~K} 9 \mathrm{ac} / \mathrm{H} 3 \mathrm{~K} 4 \mathrm{me} 3$ levels in $S_{\gamma 3}, S_{\gamma 2 \mathrm{~b}}$ and $S_{\varepsilon}$ in B cells of $3^{\prime} R R$-deficient mice compared with $w t$ mice (Fig. 6). Taken altogether, these results reveal a similar mechanistic role of the $3^{\prime} R R$ on $S$ acceptor regions during CSR and confirm its key role on Ig production ${ }^{6,7}$.
Transcriptional profiles of $\mathbf{3}^{\prime} \boldsymbol{R} R$-deficient $\mathrm{B}$ cells. Transcriptional profiles evidenced differences between splenic $B$ cells of $3^{\prime} R R$-deficient and $w t$ mice (Supplementary Table 3). Several genes implicated in interferon-related functions, inflammation, cell trafficking and B-cell homing were affected in resting B splenocytes of $3^{\prime} R R$-deficient mice (accession number GSE45230, Gene Expression Omnibus database). Since the cis-regulatory element $3^{\prime} R R$ is not expected to modulate genes outside the $\operatorname{IgH}$ locus, these differences rather involve the recently reported decreased accumulation of marginal zone $B$ cells in $3^{\prime} R R$-deficient mice $^{32}$. Accordingly, functions of the affected genes fit well with roles of marginal zone $B$ cells in infection, inflammation and immunity. After 3 days LPS + IL4 stimulation, some genes were differentially affected (Supplementary Table 4). In relations with the marked influence of the $3^{\prime} R R$ on histone modifications during CSR, inhibitors of histone acetyltransferase (Anp32a, Tle1), histone demethylase (Ecol) and histone deacetylase $(C b l-b)$ are overexpressed in stimulated $3^{\prime} R R$-deficient splenocytes as compared with $w t$ cells. In agreement with lower frequency of DSB, genes implicated in DSB detection and reparation were either downregulated (Atm, Lig4) or upregulated (Parp-3, H2afx, Ino80 and Esco1). While a direct effect of the cis-regulatory $3^{\prime} R R$ on genes located outside of the $I g H$ locus is unlikely, gene variations rather appear related to incomplete CSR. Strikingly, RNA sequencing analysis did not identify similar gene variation in LPS + IL4 stimulated AID-deficient splenic B cells (thus lacking any AID-mediated DNA lesions) compared with $w t^{32}$. This suggests that genes implicated in CSR repair are highly regulated and only transiently expressed in $w t$ cells in response to DSBs in $S_{\mu}$ and $S_{\gamma 1}$. AID-deficient and $3^{\prime} R R$-deficient mice carry CSR defect by completely different mechanisms, with, respectively, a lack of DSBs (both on $S_{\mu}$ and $S_{\gamma 1}$ ) or a biased occurrence of DSBs (normally targeting $S_{\mu}$ but not $S_{\gamma 1}$ ). Gene variations in $3^{\prime} R R$-deficient mice are thus likely not reflecting simply the lack of CSR per se, but rather the status of cells poised for CSR, some of them displaying DSBs in $S_{\mu}$, and unable to 

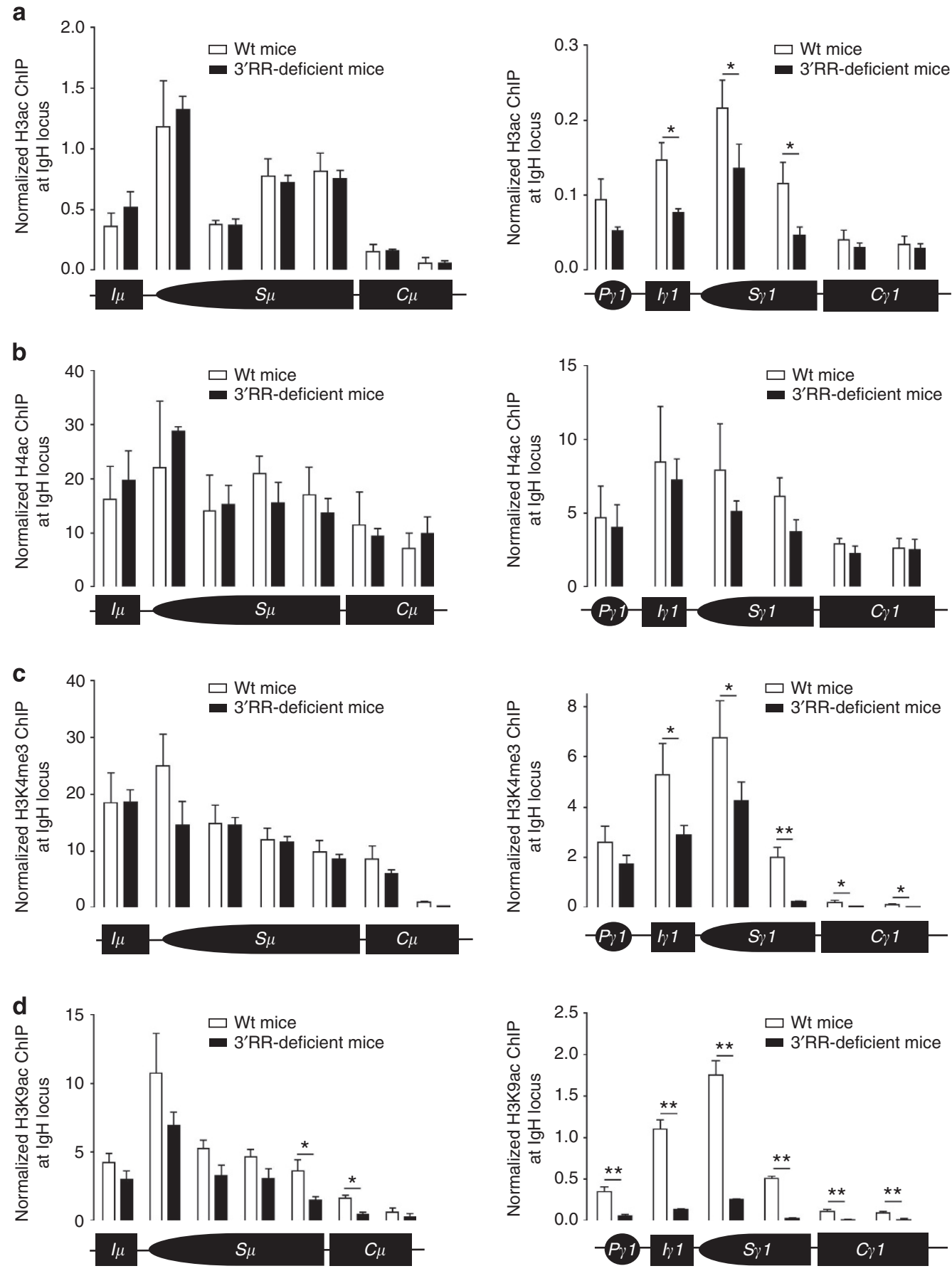

Figure 5 | Epigenetic marks (H3ac, H4ac, H3K4me3 and H3K9ac) in $\boldsymbol{S}_{\boldsymbol{\mu}}$ and $\boldsymbol{S}_{\boldsymbol{\gamma} \mathbf{1}}$ during $\mathbf{\text { IgG }} \mathbf{C}_{\mathbf{1}} \mathbf{C S R}$ in $\mathbf{3}^{\prime} \mathbf{R R}$-deficient mice. ChIP assays were performed with splenic B-cells from $3^{\prime} R R$-deficient and wt mice. Cells were stimulated with LPS + IL-4 for 2 days. Background signals from mock samples with irrelevant antibody were subtracted. Values were normalized to the total input DNA. Data are the mean \pm s.e.m. of three (for $3^{\prime} R R$-deficient mice) and six (for wt mice) independent experiments with two mice (Mann-Whitney U-test for significance).

efficiently repair these DSBs through long-range recombination with a distant acceptor region. In conclusion, we favour the hypothesis that persistent DNA damage in $S_{\mu}$ would increase the expression of genes involved in DNA-repair in $3^{\prime} R R$-deficient B cells.

miRNA analysis in $\mathbf{3}^{\prime} R \boldsymbol{R}$-deficient $B$ cells. If the hypothesis that persistent DNA damages in $S_{\mu}$ affect gene expression profiles in $3^{\prime} R R$-deficient $\mathrm{B}$-cells is correct, variation might also be evidenced at the miRNA level. To further explore how the $3^{\prime} R R$ deletion impacts the activation of B cells during CSR, we measured the expression of a panel of 84 miRNA known to be involved in B-cell development and activation. We investigated miRNA in LPS + IL4 stimulated AID-deficient splenic B-cells and found 18 downregulated miRNA and 2 up-regulated miRNA compared with $w t$ mice (Supplementary Fig. 4). In contrast, 0 miRNA were downregulated and 11 miRNA were up-regulated in $3^{\prime} R R$ deficient mice (Supplementary Fig. 4) compared with $w t$ mice. Up-regulated miRNA in $3^{\prime} R R$-deficient mice have hundreds of 

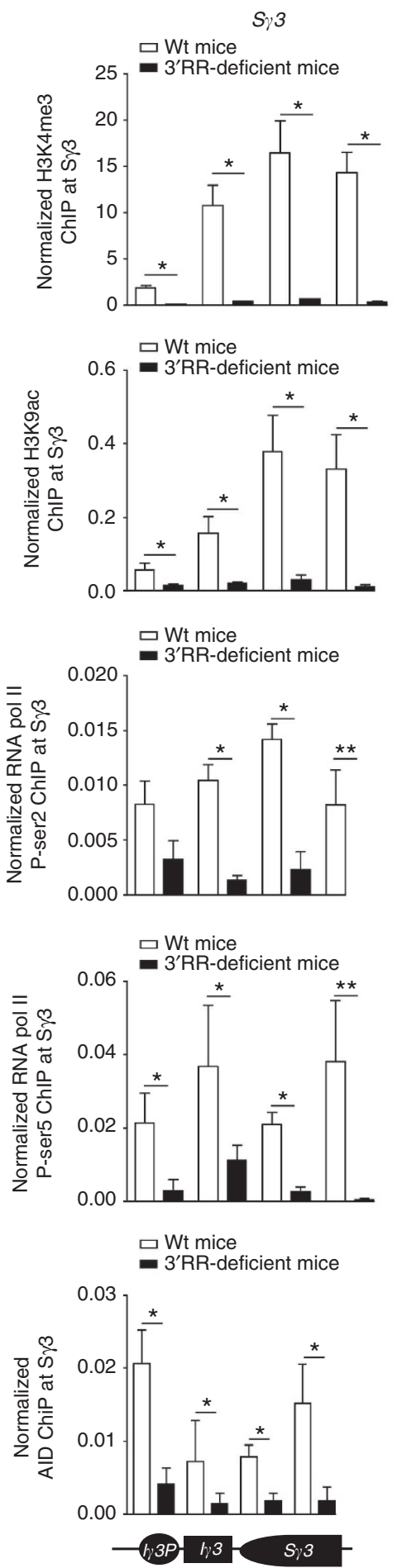
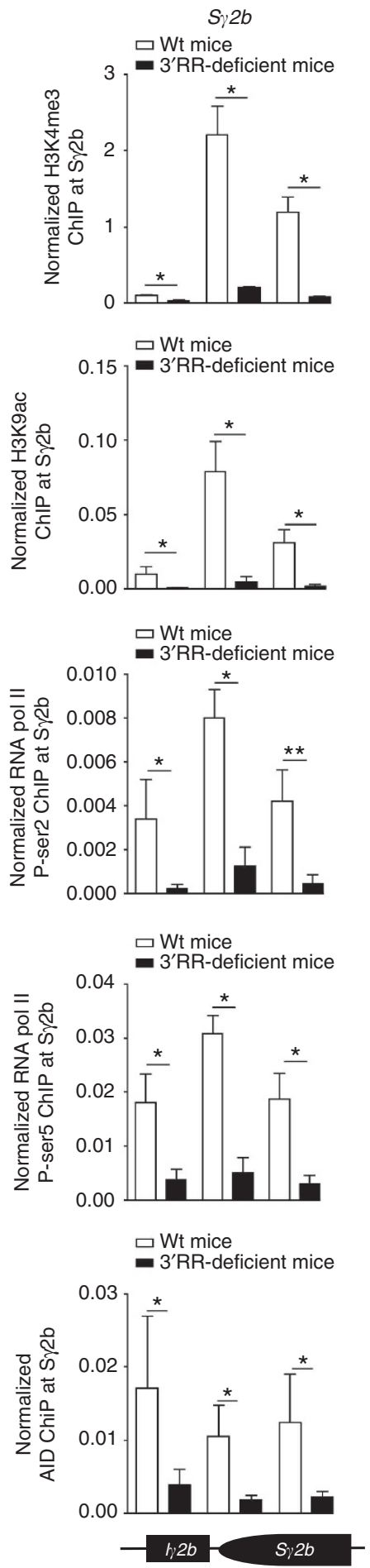
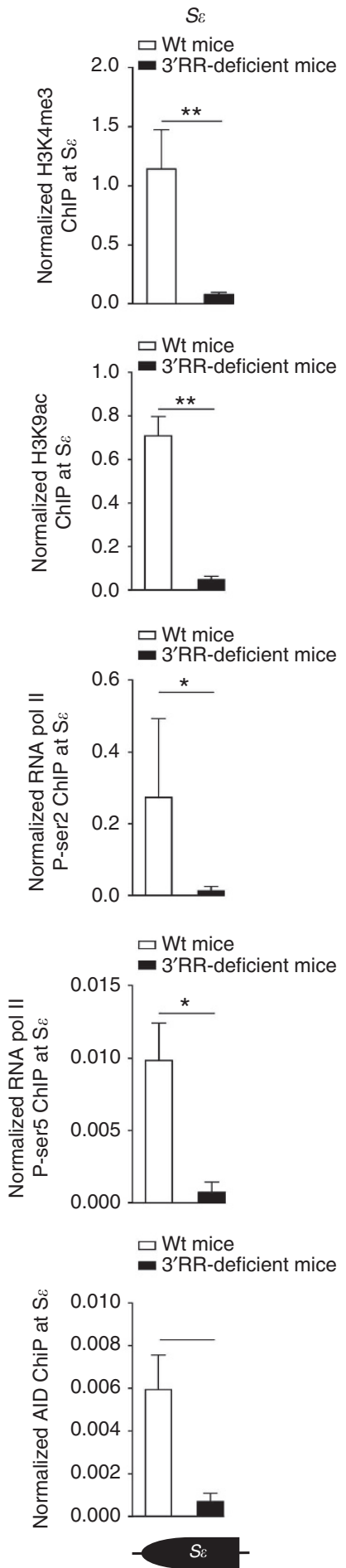

Figure 6 | Epigenetic marks, AID and pol II recruitments in $\boldsymbol{S}_{\gamma_{\mathbf{3}},} \boldsymbol{S}_{\gamma \mathbf{2 b}}$ and $\boldsymbol{S}_{\varepsilon}$ during CSR in $\mathbf{3}^{\prime} \boldsymbol{R} \boldsymbol{R}$-deficient mice. ChIP assays were performed with splenic B-cells from $3^{\prime} R R$-deficient and wt mice. Cells were stimulated with LPS for 2 days for $S_{\gamma 3}$ and $S_{\gamma 2 b}$. Cells were stimulated with LPS \pm IL4 for 2 days for $S_{\varepsilon}$. Background signals from mock samples with irrelevant antibody were subtracted. Values were normalized to the total input DNA. Data are the mean \pm s.e.m. of three to six independent experiments with two mice for each genotype (Mann-Whitney U-test for significance).

predicted targets, including Atm, Ssb1, Ino80, Exo1, Smarcd1, Dclre1b and Atmin, which have been shown to regulate DSB resection and homologous recombination ${ }^{33-38}$, and histone modifying enzymes $\mathrm{Hdac} 9$ and Escol. Interestingly, HDAC9 is required for DSB reparation by homologous reparation ${ }^{39}$, and its deletion affects antibody secretion ${ }^{40}$. Altogether, this might inhibit A-EJ, by downregulating gene implicated in micro- homology based DSB repair (Atm, Atmin, Ssb1 and Hdac9), and to favour NHEJ by upregulating Parp- $3^{41}$, and Escol, which influence the interaction between cohesion complex and DNA required for efficient $\mathrm{NHEJ}^{42,43}$. A-EJ has been shown to facilitate oncogenic translocations to $\operatorname{IgH}$ locus and to be less restricted to intrachromosomal joining than NHE ${ }^{20}$. This might be a protective mechanism limiting oncogenic translation to $S_{\mu}$, in 
which DSBs appear quite frequently while there are few in downstream acceptor regions. In parallel, LM-PCR did not show accumulation of DSBs in $S_{\mu}$ in $3^{\prime} R R$-deficient mice, despite the lack of complete CSR, suggesting that intraswitch junctions, which occur normally, are the usual mean that can be used by B cells to resolve abortive CSR issues. Finally, taken altogether results of miRNA analysis reinforce the hypothesis that the prolonged presence of DNA damage in $S_{\mu}$ would affect gene expression in $3^{\prime} R R$-deficient $\mathrm{B}$-cells rather that the hypothetical loss of $3^{\prime} R R$ trans-interactions with these genes in the nuclei.

\section{Discussion}

In the present study we show that the $3^{\prime} R R$ promotes $\operatorname{IgG}_{1}$ CSR not only by fostering germline transcription but also histone modifications (especially $\mathrm{H} 3 \mathrm{~K} 4 \mathrm{me} 3$ and $\mathrm{H} 3 \mathrm{~K} 9 \mathrm{ac}$ ), formation of $\mathrm{R}$ loops, loading and pausing of RNA Pol II, AID recruitment and finally generation of DSBs in the $S_{\gamma 1}$ region, indicating that the $3^{\prime} R R$ enhancers act as soon as these initial steps of the CSR process. In contrast to the $S_{\gamma 1}$ region, $S_{\mu}$ appears as more or less $3^{\prime} R R$-independent, suggesting that other regulatory elements are required for its CSR formatting. In a previous study Wuerffel et al. ${ }^{16}$ demonstrated with $3 \mathrm{C}$ assay and hs $3 \mathrm{~b} / \mathrm{hs} 4$-deficient mice that the $3^{\prime} R R$ interacted with the $S_{\gamma 1}$ region whereas $S_{\mu}$ was closely associated with $E_{\mu}$. Moreover the non conventional $\operatorname{IgD}$ CSR (between $S_{\mu}$ and a $S_{\delta}$-like region) occurs independently of the $3^{\prime} R R^{7}$. Our study thus validates at the DNA level the hypothesis that during CSR, the $3^{\prime} R R$ especially targets the $S$ acceptor region rather than the $S_{\mu}$ donor region. Although the $E \mu$ enhancer could be proposed to support $S_{\mu}$ accessibility when the $3^{\prime} R R$ is deleted, it is noteworthy that it is not itself mandatory for $\mathrm{CSR}^{3}$. The $3^{\prime} R R$-independence of $S_{\mu}$ is also somehow striking comparing with the known $3^{\prime} R R$-dependence of $p V_{H}$ promoters and rearranged $V D J$ regions with regards to AID recruitment and $\mathrm{SHM}^{8}$. Finally, that $S_{\gamma 1}$ accessibility to CSR is only partly altered in the absence of the $3^{\prime} R R$ allowed to study residual CSR junctions, showing that their molecular features were indiscernible from those of $w t$ junctions studied in parallel. This suggests that the $3^{\prime} R R$ contribution to CSR is restricted to the early steps of accessibility, AID recruitment and synapsis of target regions, but with no role in the repair and final resolution of CSR. Our analysis also showed that B-cells are able to transiently modify their transcriptome and miRNome during CSR to foster rapid and precise repair of DSBs, thus diminishing the risk of potentially oncogenic translocation.

\footnotetext{
Methods

Mice. The 129 wt mice (from Charles Rivers Laboratories, France) and $3^{\prime} R R$ deficient mice (from UMR CNRS 7276, Limoges, France; in a 129 background) were used. Mice of 2-3 months old (male and female) were investigated. Our research has been approved by our local ethics committee review board (Comité Régional d'Ethique sur l'Expérimentation Animale du Limousin, Limoges, France)
} and carried according the European guidelines for animal experimentation.

Spleen cell cultures for CSR. Single-cell suspensions of CD $43^{-}$spleen cells were cultured 3 days at $1 \times 10^{6}$ cells ml $^{-1}$ in RPMI 1640 with $10 \%$ fetal calf serum, $5 \mu \mathrm{g} \mathrm{ml}^{-1}$ LPS with or without $20 \mathrm{ng} \mathrm{ml}^{-1}$ IL-4 (PeproTech, Rocky Hill, NJ) ${ }^{6}$.

Cell cytometry analysis. Single-cell suspensions of cultured B cells were incubated with anti-B220-SpectralRed (PC5)-labelled antibodies (Biolegends, ref:103210,

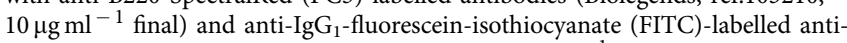
bodies (Southern Biotechnologies, ref:107002, $10 \mu \mathrm{g} \mathrm{ml}^{-1}$ final) and analysed on a Fortessa LSR2 (Beckton-Dickinson) ${ }^{44,45}$.

Cloning and sequencing of $\mathbf{S}_{\mu}-\mathbf{S}_{\boldsymbol{\gamma}}$ junctions. Three days in vitro stimulated splenocytes were harvested and DNA was extracted for investigation of $S_{\mu}-S_{\gamma 1}$ junctions. Junctions were studied using a touch-down PCR followed with a nested PCR using the following parameters: Touch-down PCR: Forward primer 5'-AGA GACCTGCAGTTGAG GCC- $3^{\prime}$ and backward primer 5-AGGATGTCCACCCT
CACCCAGGC $-3^{\prime}\left(1 \mathrm{cycle}, 98^{\circ} \mathrm{C}\right.$ for $30 \mathrm{~s} ; 2$ cycles, $98^{\circ} \mathrm{C}$ for $10 \mathrm{~s}, 69^{\circ} \mathrm{C}$ for $30 \mathrm{~s}$, $72^{\circ} \mathrm{C}$ for $90 \mathrm{~s} ; 2$ cycles, $98^{\circ} \mathrm{C}$ for $10 \mathrm{~s}, 67^{\circ} \mathrm{C}$ for $30 \mathrm{~s}, 72^{\circ} \mathrm{C}$ for $90 \mathrm{~s} ; 2$ cycles, $98^{\circ} \mathrm{C}$ for $10 \mathrm{~s}, 65^{\circ} \mathrm{C}$ for $30 \mathrm{~s}, 72^{\circ} \mathrm{C}$ for $90 \mathrm{~s} ; 25$ cycles, $98^{\circ} \mathrm{C}$ for $10 \mathrm{~s}, 60^{\circ} \mathrm{C}$ for $30 \mathrm{~s}, 72^{\circ} \mathrm{C}$ for $90 \mathrm{~s} 1$ cycle, $72^{\circ} \mathrm{C}$ for $\left.7 \mathrm{~min}\right)$. Nested PCR: Forward primer $5^{\prime}$-CCAGCCACA GTAATGACCCAG- $3^{\prime}$ and backward primer $5^{\prime}$-TTGTTATCCCCCATCCTGTC ACCT- $3^{\prime}\left(1\right.$ cycle, $98^{\circ} \mathrm{C}$ for $30 \mathrm{~s} ; 35$ cycles, $98^{\circ} \mathrm{C}$ for $10 \mathrm{~s}, 65^{\circ} \mathrm{C}$ for $30 \mathrm{~s}, 72^{\circ} \mathrm{C}$ for $90 \mathrm{~s} ; 1$ cycle, $72^{\circ} \mathrm{C}$ for $7 \mathrm{~min}$ ). The PCR products were cloned into the Zero Blunt Topo PCR cloning (Invitrogen). Plasmids were isolated using the NucleoSpin kit (Macherey-Nagel Eurl) and sequenced using an automated laser fluorescent ANA ABI-PRISM sequencer (Perkin-Elmer).

Southern blotting of $\mathbf{C}_{\mu}-\mathbf{C}_{\gamma 1}$ junctions. $S_{\mu}-S_{\gamma 1}$ junctions amplified as previously described were subjected to $1 \%$ agarose gel electrophoresis, and transferred overnight on a positively charged Nylon hybridization membrane (MP Biomedicals). A $507 \mathrm{bp}$ probe was amplified using the following primers: Forward primer $5^{\prime}$ GGCAGATTAGAATGAATGCACCTG-3' , backward primer 5' -TTGTTATCC CCCATCCTGTCACCT and ${ }^{32} \mathrm{P}$-labelled using Amersham Rediprime II Random Prime Labelling System (GE Healthcare) according to the manufacturer protocol. The membranes were saturated with salmon sperm DNA $\left(4 \mathrm{mg} \mathrm{ml}^{-1}\right)$ and incubated with the labelled probe overnight at $42^{\circ} \mathrm{C}$. Membrane were then washed for 15 minutes twice at room temperature in $2 \mathrm{X}$ SSC buffer $+0.1 \%$ SDS, then 5 minutes at $52^{\circ} \mathrm{C}$ in $0.1 \mathrm{X} \mathrm{SSC}+0.5 \%$ SDS. Membranes were autoradiographed on X50 hyperfilm MP (GE Healthcare) at $-80^{\circ} \mathrm{C}$ for 6 hours and revealed using Carestream Kodak autoradiography GBX developer and fixer (Sigma Aldrich).

IgG $\mathbf{1}_{\mathbf{1}}$ Elisa assays. Blood samples were recovered from 12 weeks-old transgenic mice and $w t$ controls. Serum samples were recovered by centrifugation and stored at $-20^{\circ} \mathrm{C}$ until used. B splenocytes were cultured for 3 days with LPS + IL4. At day $3,1 \times 10^{6}$ cells were cultured for $24 \mathrm{~h}$ in growth medium without LPS + IL4 Culture supernatants were recovered and stored at $-20^{\circ} \mathrm{C}$ until used. Culture supernatants and sera were analysed for the presence of $\operatorname{IgG}_{1}$ by ELISA $^{6,44,45}$. ELISA assays were performed in polycarbonate 96 multiwell plates, coated overnight at $4{ }^{\circ} \mathrm{C}\left(100 \mu \mathrm{l}\right.$ per well) with $2 \mu \mathrm{g} \mathrm{ml}^{-1} \mathrm{IgG}_{1}$ (Cell Lab, ref:731863) in $0.05 \mathrm{M} \mathrm{Na}_{2} \mathrm{CO}_{3}$ buffer. After three successive washing steps in phosphate-buffered saline (PBS) buffer, a blocking step was performed (3\% bovine serum albumin (BSA) in PBS) for $30 \mathrm{~min}$ at $37^{\circ} \mathrm{C}$. After three washing steps, $50 \mu \mathrm{l}$ of sera (first diluted to 1:50), supernatants or standard $\mathrm{IgG}_{1}$ (Beckman Coulter, ref:731907, $1 \mathrm{mg} \mathrm{ml}^{-1}$, first diluted to 1:50) were diluted into successive wells in $1 \%$ BSA/PBS buffer and incubated for $2 \mathrm{~h}$ at $37^{\circ} \mathrm{C}$. After three washing steps, $100 \mu \mathrm{l}$ per well of $1 \mu \mathrm{g} \mathrm{ml}^{-1} \mathrm{AP}$-conjugated goat anti-mouse $\mathrm{IgG}_{1}$ (Southern Biotechnologies, ref: 1070041) were incubated for $2 \mathrm{~h}$ at $37^{\circ} \mathrm{C}$. After washing, AP activity was assayed on $1 \mathrm{mg} \mathrm{ml}^{-1} \mathrm{AP}$ substrate, and blocked with addition of $3 \mathrm{M} \mathrm{NaOH}$. Optic density was then measured at $400 \mathrm{~nm}$.

Quantitative PCR of $\mathbf{I}_{\gamma 1}-C_{\gamma \mathbf{1}}$ and $\mathbf{I}_{\mu}-\mathbf{C}_{\gamma \mathbf{1}}$ transcripts. Two days in vitro stimulated splenocytes were collected and RNA was extracted for investigation of $I_{\gamma 1}-C_{\gamma 1}$ transcripts. RNA and cDNA were prepared using standard techniques.

Quantitative PCR was performed using power SYBR green (Applied Biosystems): $I_{\gamma 1}$ forward primer: 5'-GGCCCTTCC AGATCTTTGAG-3'; $C_{\gamma 1}$ reverse primer: $5^{\prime}$-ATGGAGTTAGTTTGGGCAGCA- $3^{\prime}$. I $\mu$ forward primer: $5^{\prime}$-ACCTGGGAAT GTATGGTTGTGGCTT- $3^{\prime}$. $C_{\mu}$ reverse primer $5^{\prime}$-TCTGAACCTTCAAGGATGC TCTTG-3'. $I_{\gamma 1}-C_{\gamma 1}$ and $I_{\mu}-C_{\gamma 1}$ transcripts were normalized to Gapdh transcripts (reference Mm99999915-g1).

ChIP experiments. Splenic B cells were purified by CD43 magnetic cell sorting from nonimmunized mice and cultured in vitro with $5 \mu \mathrm{g} \mathrm{ml}^{-1}$ LPS with or without $20 \mathrm{ng} \mathrm{ml}^{-1}$ IL4 for 2 days. ChIP experiments were done essentially as previously described ${ }^{8}$. In brief, $3 \times 10^{7}$ stimulated B cells were cross-linked at $37^{\circ} \mathrm{C}$ for $15 \mathrm{~min}$ in $15 \mathrm{ml}$ PBS with $1 \%$ formaldehyde. The reaction was quenched with $0.125 \mathrm{M}$ glycine. After lysis, chromatin was sonicated to $0.5-1 \mathrm{~kb}$ using a Vibracell 75043 (Thermo Fisher Scientific). After dilution in ChIP buffer (0.01\% SDS, 1.1\% Triton X-100, $1.2 \mathrm{mM}$ EDTA, $16.7 \mathrm{mM}$ Tris- $\mathrm{HCl}, \mathrm{pH} 8.1$, and $167 \mathrm{mM} \mathrm{NaCl}$ ), chromatin was precleared by rotating for $2 \mathrm{~h}$ at $4{ }^{\circ} \mathrm{C}$ with $100 \mu \mathrm{l}$ of $50 \%$ protein A/G slurry $\left(0.2 \mathrm{mg} \mathrm{ml}^{-1}\right.$ sheared salmon sperm DNA, $0.5 \mathrm{mg} \mathrm{ml}^{-1} \mathrm{BSA}$, and $50 \%$ protein A/G; Sigma). $0.3-0.5 \times 10^{6}$ cell equivalents were saved as input, and $3-5 \times 10^{6}$ cell equivalents were incubated overnight with specific or control antibodies. Immune complexes were precipitated by the addition of protein $\mathrm{A} / \mathrm{G}$ Cross-linking was reversed by overnight incubation $\left(70^{\circ} \mathrm{C}\right)$ in TE buffer with $0.02 \%$ SDS and chromatin was phenol/chloroform extracted. PCR primers used for Q-PCR are detailed in the Supplementary Table 2. The following antibodies were used: anti-H3K4me3 (Millipore, 07-473), anti-H3K9ac (Millipore, 06-942), antiH3ac (Millipore, 06-599), anti-H4ac (Millipore, 06-866), anti-RNA Pol II P-ser2 (Abcam, ab5095) and anti-RNA Pol II P-ser 5 (Abcam, ab5131). Anti-AID antibodies were kindly provided by Dr P. Gearhart.

Ligation-mediated PCR. LM-PCR was used to highlight the presence of DSBs in $S_{\mu}$ and $S_{\gamma 1}$. LM-PCR experiments were schematized in the Supplementary Fig. $1 \mathrm{~b}$. Splenocytes were stimulated with LPS + IL4 for 2 days. Genomic DNA was 
extracted and treated with T4 DNA polymerase which trims back $3^{\prime}$ overhangs while 'filling in' 3 '-recessed ends, thereby yielding blunt $5^{\prime}$-phosphorylated DNA ends. DNA was then ligated with T4 DNA ligase with the double-strand anchor linker $\mathrm{BW}^{22}$. DSBs were detected by semi-nested LM-PCR using BW1 primer targeting the BW linker sequence and a primer specific to $S_{\mu}$ or $S_{\gamma 1}$. DSB were studied after hybridization with ${ }^{32} \mathrm{P}$-labelled probes located on $S_{\mu}$ and $S_{\gamma 1}$, respectively.

R loops. $\mathrm{R}$ loops were analysed using bisulfite conversion of single-strand $\mathrm{DNA}^{46}$. $\mathrm{R}$ loop experiments were schematized in the Supplementary Fig. 1c. Splenic B-cells from $w t$ and $3^{\prime} R R$-deficient mice were stimulated in vitro with $5 \mu \mathrm{g} \mathrm{ml}{ }^{-1}$ LPS and $20 \mathrm{ng} \mathrm{ml}^{-1}$ IL4 for 2 days. DNA was extracted and purified using Phase Lock gel (5 Prime), and digested with EcoRI (New England Biolabs) for $8 \mathrm{~h}$. DNA was bisulfite converted using the EpiMark Bisulfite Conversion Kit (New England Biolabs). Five micrograms were incubated in Bisulfite mix at $37^{\circ} \mathrm{C}$ for $15 \mathrm{~h}$. Converted DNA was then desulfonated and purified according to the manufacturer protocol, and resuspended in $60 \mu \mathrm{H}_{2} \mathrm{O}$. We made touch-down PCR reaction (One Taq Hot start DNA polymerase, NEB) using a forward native primer and a reverse primer designed to match the converted sequence. For $S_{\mu}$ : forward primer $5^{\prime}$-GCT GCTCTTAAAGCTTGT AAACTGTTTCT- $3^{\prime}$ and backward primer 5-CTCACCC CATCTCAACTACTCCAAAA TAA- $3^{\prime}$; $\left(1\right.$ cycle, $94^{\circ} \mathrm{C}$ for $30 \mathrm{~s} ; 3$ cycles, $94^{\circ} \mathrm{C}$ for $15 \mathrm{~s}, 56^{\circ} \mathrm{C}$ for $30 \mathrm{~s}, 68^{\circ} \mathrm{C}$ for $120 \mathrm{~s} ; 3$ cycles, $94^{\circ} \mathrm{C}$ for $15 \mathrm{~s}, 55^{\circ} \mathrm{C}$ for $30 \mathrm{~s}, 68^{\circ} \mathrm{C}$ for $120 \mathrm{~s} ; 3$ cycles, $94^{\circ} \mathrm{C}$ for $15 \mathrm{~s}, 54^{\circ} \mathrm{C}$ for $30 \mathrm{~s}, 68^{\circ} \mathrm{C}$ for $120 \mathrm{~s} ; 25$ cycles, $94^{\circ} \mathrm{C}$ for $15 \mathrm{~s}$, $53^{\circ} \mathrm{C}$ for $30 \mathrm{~s}, 68^{\circ} \mathrm{C}$ for $120 \mathrm{~s} ; 1$ cycle, $68^{\circ}$ for $5 \mathrm{~min}$ ). For $S_{\gamma 1}$ : forward primer $5^{\prime}$-TTCCAGATCTTTGAGTCATCCTATC- $3^{\prime}$ and backward primer 5-CACCCAT CAACTCTA ACCATATAATATTTACTC- $3^{\prime}$; $\left(1\right.$ cycle, $94^{\circ} \mathrm{C}$ for $30 \mathrm{~s} ; 3$ cycles, $94^{\circ} \mathrm{C}$ for $15 \mathrm{~s}, 52^{\circ} \mathrm{C}$ for $30 \mathrm{~s}, 68^{\circ} \mathrm{C}$ for $120 \mathrm{~s} ; 3$ cycles, $94^{\circ} \mathrm{C}$ for $15 \mathrm{~s}, 51^{\circ} \mathrm{C}$ for $30 \mathrm{~s}$, $68^{\circ} \mathrm{C}$ for $120 \mathrm{~s} ; 3$ cycles, $94^{\circ} \mathrm{C}$ for $15 \mathrm{~s}, 50^{\circ} \mathrm{C}$ for $30 \mathrm{~s}, 68^{\circ} \mathrm{C}$ for $120 \mathrm{~s} ; 25$ cycles, $94^{\circ} \mathrm{C}$ for $15 \mathrm{~s}, 49^{\circ} \mathrm{C}$ for $30 \mathrm{~s}, 68^{\circ} \mathrm{C}$ for $120 \mathrm{~s} ; 1$ cycle, $68^{\circ}$ for $5 \mathrm{~min}$ ). The PCR products were cloned and sequenced as described for $S_{\mu}-S_{\gamma 1}$ junctions.

Transcriptome analysis. mRNA was extracted from B220 ${ }^{+}$splenic B-cells of $3^{\prime} R R$-deficient mice and $w t$ mice before and after 3 days LPS + IL4 stimulation. Microarray experiments were done in 'Nice - Sophia Antipolis Microarray Facility' (France). Statistical analysis was made with the Bioconductor open source software, particularly its Limma package ${ }^{47-50}$. The microarray data presented in this article have been submitted to the Gene Expression Omnibus database (www.ncbi.nlm.nih.gov/geo/) under the accession numbers GSE45230.

miRNA analysis. Splenic B cells from $w t$, AID-deficient mice and $3^{\prime} R R$-deficient mice were stimulated in vitro with $5 \mathrm{\mu g} \mathrm{ml}^{-1}$ LPS and $20 \mathrm{ng} \mathrm{ml}^{-1}$ IL4 for 2 days, and total RNA was extracted. cDNA was prepared using QIAGEN miScript II RT kit, and expression of a panel of 84 miRNA was determined using QIAGEN miScript miRNA PCR Array Mouse T-Cell and B-Cell activation, according to the manufacturer's protocol. miRNA targets predictions were made using the http://mirdb.org/ website ${ }^{51}$.

\section{References}

1. Henderson, A. \& Calame, K. Transcription regulation during B cell development. Annu. Rev. Immunol. 16, 163-200 (1998).

2. Pinaud, E. et al. The IgH locus 3' regulatory region: pulling the strings from behind. Adv. Immunol. 110, 27-70 (2011).

3. Perlot, T., Alt, F. W., Bassing, C. H., Suh, H. \& Pinaud, E. Elucidation of IgH intronic enhancer functions via germ-line deletion. Proc. Natl Acad. Sci. USA 42, 14362-14367 (2005)

4. Marquet, M. et al. The E $\mu$ enhancer region influences $\mathrm{H}$ chain expression and $\mathrm{B}$ cell fate without impacting IgVH repertoire and immune response in vivo. J. Immunol. 193, 1171-1183 (2014).

5. Saintamand, A. et al. The $\operatorname{IgH} 3$ ' regulatory region governs $\mu$ chain transcription in mature B lymphocytes and the B cell fate. Oncotarget 6, 4845-4852 (2015).

6. Vincent-Fabert, C. et al. Genomic deletion of the whole IgH 3' regulatory region (hs3a, hs1,2, hs3b, hs4) dramatically affects class switch recombination and Ig secretion to all isotypes. Blood 116, 1895-1898 (2010).

7. Rouaud, P. et al. Elucidation of the enigmatic IgD class switch recombination via germ-line deletion of the IgH 3' regulatory region. J. Exp. Med. 211, 975-985 (2014).

8. Rouaud, P. et al. The IgH 3' regulatory region controls AID-induced somatic hypermutation in germinal centre B-cells in mice. J. Exp. Med. 210, 1501-1507 (2013).

9. Rouaud, P. et al. Enhancers located in heavy chain regulatory region (hs3a, hs1,2, hs3b and hs4) are dispensable for diversity of VDJ recombination. J. Biol. Chem. 287, 8356-8360 (2012).

10. Medvedovic, J. et al. Flexible long-range loops in the $\mathrm{VH}$ gene region of the Igh locus that likely facilitate the generation of a diverse antibody repertoire. Immunity 39, 229-244 (2013).

11. Yan, T. C. et al. IgH class switching and translocations used a robust nonclassical end-joining pathway. Nature 449, 478-483 (2007).

12. Stavnezer, J., Björkman, A., Du, L., Cagigi, A. \& Pan-Hammarström, Q. Mapping of switch recombination junctions, a tool for studying DNA repair pathways during immunoglobulin class switching. Adv. Immunol. 108, 45-109 (2010).

13. Boboila, C., Alt, F. W. \& Schwer, B. Classical and alternative end-joining pathways for repair of lymphocyte-specific and general DNA double-strand breaks. Adv. Immunol. 116, 1-45 (2012).

14. Matthews, A. J., Zheng, S., DiMenna, L. J. \& Chaudhuri, J. Regulation of immunoglobulin class-switch recombination: choreography of noncoding transcription, targeted DNA deamination, and long-range DNA repair. $A d v$. Immunol. 122, 1-57 (2014).

15. Vaidyanathan, B., Yen, W. F., Pucella, J. N. \& Chaudhuri, J. AIDing chromatin and transcription-coupled orchestration of immunoglobulin class-switch recombination. Front. Immunol. 5, 120 (2014).

16. Wuerffel, R. et al. S-S synapsis during class switch recombination is promoted by distantly located transcriptional elements and activation-induced deaminase. Immunity 27, 711-722 (2007).

17. Cogné, M. et al. A class switch control region at the 3' end of the immunoglobulin heavy chain locus. Cell 77, 737-747 (1994).

18. Pinaud, E. et al. Localization of the 3' IgH locus elements that effect longdistance regulation of class switch recombination. Immunity 15, 187-199 (2001)

19. Xu, M. \& Stavnezer, J. Regulation of transcription of immunoglobulin germline $\gamma 1$ RNA: analysis of the promoter/enhancer. EMBO J. 11, 145-155 (1992)

20. Boboila, C. et al. Alternative end-joining catalyses robust IgH locus deletions and tranlocations in the combined absence of ligase 4 and ku70. Proc. Natl Acad. Sci. USA 107, 3034-3039 (2010).

21. Laffleur, B. et al. AID-induced remodelling of immunoglobulin genes and B cell fate. Oncotarget 5, 1118-1131 (2014).

22. Zan, H. \& Casali, P. AID- and UNG-dependent generation of staggered douvlestrand DNA breaks in immunoglobulin class switch DNA recombination: a post-cleavage role for AID. Mol. Immunol. 46, 45-61 (2008).

23. Kracker, S. et al. Impaired induction of DNA lesions during immunoglobulin class-switch recombination in humans influences end-joining repair. Proc. Natl Acad. Sci. USA 107, 22225-22230 (2010).

24. Kenter, A. L. AID targeting is dependent on RNA polymerase II pausing. Semin. Immunol. 24, 281-286 (2012).

25. Kuang, F. L., Luo, Z. \& Scharff, M. D. H3 trimethyl K9 and H3 acetyl K9 chromatin modifications are associated with class switch recombination. Proc. Natl Acad. Sci. USA 106, 5288-5293 (2009).

26. Stanlie, A., Masatoshi, A., Muramatsu, M., Honjo, T. \& Begum, N. A. Histone3 lysine4 trimethylation regulated by the facilitates chromatin transcription complex is critical for DNA cleavage in class switch recombination. Proc. Natl Acad. Sci. USA 107, 22190-22195 (2010).

27. Jeevan-Raj, B. P. et al. Epigenetic tethering of AID to the donor switch region during immunoglobulin class switch recombination. J. Exp. Med. 208, 1649-1660 (2011).

28. Daniel, J. A. \& Nessenzweig, A. Roles for histone H3K4 methyltransferase activities during immunoglobulin class-switch recombination. Biochim. Biophys. Acta 1819, 733-738 (2012).

29. Bühler, M., Mohn, F., Stalder, L. \& Mühlemann, O. Transcriptional silencing of nonsense codon-containing immunoglobulin minigenes. Mol. Cell. 18, 307-317 (2005).

30. Lu, Z. P., Ju, Z. L., Shi, G. Y., Zhang, J. W. \& Sun, J. Histone deacetylase inhibitor trichostatin A reduces anti-DNA autoantibody production and represses IgH gene transcription. Biochem. Biophys. Res. Commun. 330, 204-209 (2005).

31. Kurosawa, K., Lin, W. \& Ohta, K. Distinct roles of HDAC1 and HDAC2 in transcription and recombination at the immunoglobulin loci in the chivken $\mathrm{B}$ cell line DT40. J. Biochem. 148, 201-207 (2010).

32. Fritz, E. L. et al. A comprehensive analysis of the effects of the deaminase AID on the transcriptome and methylome of activated B cells. Nat. Immunol. 14, 749-755 (2013).

33. Yang, S. H. et al. The SOSS1 single-stranded DNA binding complex promotes DNA end resection in concert with Exo1. EMBO J. 32, 126-139 (2013).

34. Loizou, J. I. et al. ATMIN is required for maintenance of genomic stability and suppression of B cell lymphoma. Cancer Cell. 19, 587-600 (2011).

35. Bolderson, E. et al. Phosphorylation of Exo1 modulates homologous recombination repair of DNA double-strand breaks. Nucleic Acids Res. 38, 1821-1831 (2010).

36. Bennett, G., Papamichos-Chronakis, M. \& Peterson, C. L. DNA repair choice defines a common pathway for recruitment of chromatin regulators. Nat. Commun 4, 2084 (2013).

37. Costelloe, T. et al. The yeast Fun30 and human SMARCAD1 chromatin remodellers promote DNA and resection. Nature 489, 581-586 (2012).

38. Wu, P., Takai, H. \& de Lange, T. Telomeric 3'overhangs derive from resection by Exol and Apollo and fill-in by POT1b-associated CST. Cell 150, 39-52 (2012).

39. Kotian, S., Liyanarachchi, S., Zelent, A. \& Parvin, J. D. Histone deacetylases 9 and 10 are required for homologous recombination. J. Biol. Chem. 286, $7722-7726$ (2011). 
40. Yan, K. et al. Histone deacetylase 9 deficiency protects against effector T cell-mediated systemic autoimmunity. J. Biol. Chem. 286, 28833-28843 (2011).

41. Rulten, S. L. et al. PARP-3 and APLF function together to accelerate nonhomologous end-joining. Mol. Cell. 41, 33-45 (2011).

42. Sjögren, C. \& Ström, L. S-phase and DNA damage activated establishment of sister chromatid cohesion-importance for DNA repair. Exp. Cell. Res. $\mathbf{3 1 6}$ 1445-1453 (2010).

43. Thomas-Claudepierre, A. S. et al. The cohesion complex regulates immunoglobulin class switch recombination. J. Exp. Med. 210, 2495-2502 (2013).

44. Truffinet, V. et al. The 3' IgH locus control region is sufficient to deregulate a $\mathrm{c}$-myc transgene and promote mature $\mathrm{B}$ cell malignancies with a predominant Burkitt-like phenotype. J. Immunol. 179, 6033-6042 (2007).

45. Vincent-Fabert, C. et al. Ig synthesis and class switching do not require the presence of the hs4 enhancer in the 3' IgH regulatory region. J. Immunol. 182, 6926-6932 (2009).

46. Yu, K., Chedin, F., Hsieh, C. L., Wilson, T. E. \& Lieber, M. R. R-loops at immunoglobulin class switch regions in the chromosomes of stimulated B cells. Nat. Immunol. 4, 442-451 (2003).

47. Rouaud, P. et al. Mantle cell lymphoma-like lymphomas in c-myc-3'RR/ p53 + /- mice and c-myc-3'RR/Cdk4R24C mice: differential oncogenic mechanisms but similar cellular origin. Oncotarget 3, 586-593 (2012).

48. Le Brigand, K. \& Barbry, P. MEDIANTE: a web-based microarray data manager. Bioinformatics 23, 1304-1306 (2007).

49. Le Brigand, K. et al. An open-access long oligonucleotide microarray resource for analysis of the human and mouse transcriptomes. Nucleic Acids Res. 34, e87 (2006).

50. Smyth, G. K. Linear models and empirical Bayes methods for assessing differential expression in microarray experiments. Stat. Appl. Genet. Mol. Biol 3, article 3 (2004).

51. Wang, X. \& El Naqa, I. M. Prediction of both conserved and nonconserved microRNA targets in animals. Bioinformatics 24, 325-332 (2008).

\section{Acknowledgements}

This work was supported by grants from Conseil Régional du Limousin, Association pour la Recherche sur le Cancer (SL 220100601332 and PJA 20141201649), ANR (Projets Blanc 2011), Ligue Contre le Cancer (comité de la Correze), and 'Lions Club de la Corrèze, Zone 33 district 103 Sud'. Epigenetic experiments were supported by a specific grant from INCa-Cancéropôle GSO (2014). M. Cogné is supported by Institut Universitaire de France and Fondation pour la Recherche Médicale. P. Rouaud had a fellowship from ARC (DOC20130606964). We acknowledge the technological expertise of the Nice Sophia-Antipolis Functional Genomics Platform, supported by MICROENVIMET, FP7-HEALTHF2-2008-201279, the ARC, and the INCa. We thank Dr P. Barbry for helpful discussions and support during this work. We thank S. Desforges and B. Remerand for help with animal care. We thank Dr P. Gearhart for sending us anti-AID antibodies.

\section{Author contributions}

P.R., A.S., F.S., M.C. and Y.D. actively participated to the experimental design of the study. G.R. performed transcriptome experiments. M.C. and Y.D. participated in the scientific discussion for manuscript writing, obtained financial grants and agreement of the ethic committee of our institution to perform the study.

\section{Additional information}

Supplementary Information accompanies this paper at http://www.nature.com/ naturecommunications

Competing financial interests: The authors declare no competing financial interests.

Reprints and permission information is available online at http://npg.nature.com/ reprintsandpermissions/

How to cite this article: Saintamand, A. et al. Elucidation of $\operatorname{IgH~} 3^{\prime}$ region regulatory role during class switch recombination via germline deletion. Nat. Commun. 6:7084 doi: $10.1038 /$ ncomms8084 (2015). 